\title{
Changes in Ovarian Cancer Prognosis, Ten Years Single Center Experience
}

\section{Over Kanseri Prognozunda Değişiklikler, On Yıllık Tek Merkez Deneyimi}

\author{
İrem Bilgetekin ${ }^{1}$, Ece Esin ${ }^{1}$, Fatma Buğdaycı Başal ${ }^{1}$, Umut Demirci ${ }^{2}$, Berna Öksüzoğlu ${ }^{1}$ \\ ${ }^{1}$ Sağlık Bilimleri Üniversitesi, Dr Abdurrahman Yurtaslan Ankara Onkoloji Eğitim Ve Araştırma \\ Hastanesi,Tıbbi Onkoloji Kliniği, Ankara \\ ${ }^{2}$ Üsküdar Üniversitesi, Memorial Ankara Hastanesi, Tıbbi Onkoloji Kliniği, Ankara, Türkiye
}

$\underline{\text { Dergiye Ulaşma Tarihi:29.06.2020 Dergiye Kabul Tarihi:13.07.2020 Doi: }}$

\section{ÖZET}

GİRIŞ ve AMAÇ: Over kanseri kadınlarda görülen beşinci en sık kanser olmakla birlikte jinekolojik kanserlere bağlı ölüm nedenleri arasında ilk sırada yer almaktadır. Çalışmamızda merkezimizde over kanseri nedeniyle tedavi verilen hastaların nüks durumunun, sağkalım sonuçlarının ve tedaviye bağlı gözlenen yan etkilerin retrospektif olarak değerlendirilmesi amaçlanmıştır.

YÖNTEM ve GEREÇLER: Çalışmamızda Ocak 2010 -Ocak 2020 yılları arasında Dr. Abdurrahman Yurtaslan Ankara Onkoloji Eğitim ve Araştırma Hastanesi Medikal Onkoloji Kliniğinde tanı ve tedavi amacıyla takibi yapılmış over kanserli 160 olgunun tıbbi kayıtları sistem notları ve dosyalarından retrospektif olarak incelenmiştir. Çalışmamıza over kanseri tanısı almış 18 yaş ve üzeri hastalar dahil edildi. Olgular yaş ortalamasına, over kanseri histopatolojik tiplerine, tanı anındaki evreye, aldıkları kemoterapiye bağlı görülen yan etkilerine, progresyonsuz sağkalım (PFS) ve genel sağkalım (GS) sürelerine göre ayrıntılı olarak incelenmiştir. Sağkalım sürelerinin hesaplanmasında Kaplan-Meier analizi kullanıldı.

BULGULAR: Çalışmaya alınan 160 hastanın ortanca yaşı $61 \pm 11$ idi. Histopatolojik alt gruplara göre en sık $(\% 80,6)$ seröz epitelyal over kanseri saptandı. Tanı esnasındaki evre dağılımı incelendiğinde olguların en çok Evre III'de tanı aldığı görüldü. Kemoterapiye bağlı en sik görülen yan etki alopesi (\%100) olurken; alopesi dışında yan etki görülme insidansı $\% 51,2$ olarak bulundu. Olguların $\% 48,8$ 'inde nüks saptanırken; medyan progresyonsuz sağkalım 19,1 ay; tüm grupta ise genel sağkalım 89,9 ay olarak hesaplandı. Doz azaltımı yapılan olgularda ise genel sağkalım anlamlı olarak düşük bulundu $(\mathrm{p}<0,05)$.

TARTIŞMA ve SONUÇ: Çalışmamız olguların yaş ortalaması, hastalığın tanıdaki evresi, kemoterapi yan etkileri, sağkalım oranları açısından diğer çalışmalarla benzerlik göstermektedir. Doz azaltımının genel sağkalım üzerine olan negatif etkisi ise çoğu çalı̧̧ma ile benzerlik göstermekle birlikte bu konuda yapılacak yeni araştırmaların gerekliliği göze çarpmaktadır.

Anahtar Kelimeler: Kemoterapi, Over kanseri, Yan etki

\begin{abstract}
INTRODUCTION: Ovarian cancer is the fifth most common cancer in women and ranks first among the causes of death due to gynecological cancers. In our study, we aimed to evaluate the recurrence status, survival outcomes and treatment-related side effects of patients treated for ovarian cancer retrospectively.

METHODS: The study is performed at Dr.Abdurrahman Yurtaslan Ankara Oncology Training and Research Hospital. In this study, 160 patients with ovarian cancer who were followed up for diagnosis and treatment between January 2010 and January 2020 were analyzed retrospectively. The cases were analyzed according to the average age, histopathological types of the ovarian cancer, the stage at the time of diagnosis, the side effects associated with the chemotherapy, the progression-free survival (PFS) and overall survival (OS) rates.Log-Rank test was used to determine survival times.

RESULTS: The median age of patients included in the study is $61 \pm 11$ (50-72). Serous epithelial ovarian cancer was the most common (80.6\%) according to histopathological subgroups. When the stage distribution at the time of diagnosis was examined, it was seen that the cases were mostly diagnosed in Stage III. While the most common side effect associated with chemotherapy was alopecia (100\%), the incidence of side effects other than alopecia was $51.2 \%$. Recurrence was detected in $48.8 \%$ of the cases, and median progression-free survival was 19.1 months, and overall survival was 89.9 months in the whole group.. Overall survival was significantly low in cases with dose reduction $(\mathrm{p}<0.05)$.
\end{abstract}


DISCUSSION AND CONCLUSION: The present study shows similarity with other studies in terms of mean age, stage of diagnosis, chemotherapy side effects, survival rates. The negative effect of dose reduction on overall survival is similar to most studies, but the necessity of new research on this subject is noticeable.

Keywords: Chemotherapy, Ovarian Cancer, Side Effects

\section{GİRIS}

Jinekolojik maligniteler arasında over kanseri en s1k görülen ikinci kanser tipi olmakla birlikte mortalitede ilk sirada yer almaktadır. Over malignitelerinin \%95'inden fazlasın ise epitelyal over kanseri (EOK) oluşturmaktadır (1). Over kanserinin kliniği akut veya subakut olarak seyretmektedir. Akut olgular plevral efüzyon, ileus ve venöz tromboembolizm gibi durumlarla ortaya çıkmaktadır. Subakut vakalarda karında şişkinlik, adneksiyal kitle, pelvik veya karın ağrıs1 ve gastrointestinal semptomlar gibi spesifik olmayan bulgular görülebilmektedir (2).

Over kanserleri sıklıkla geç tanı almakta ve çoğu kez hastalık Evre III veya IV'e ilerleyene kadar fark edilememektedir. Geç tanı hastalığın sağkalım oranını en çok etkileyen faktör olarak gösterilmektedir. Güncel veriler, over kanserinde 5 yıllık sağkalım oranlarının \% 47-48 aralığında olduğunu bildirmektedir (3). gösteren çalışmalar da bulunmaktadır (5). Over kanserleri patolojik ve cerrahi bulgular esas alınarak FIGO evrelemesine göre siniflandırılır (6). Erken evre over kanserlerinde radikal cerrahi tercih edilirken; ileri evre kanserlerde sitoredüktif cerrahi uygulanmaktadır. Sitoredüktif cerrahide cerrahi sonrası kalan tümör nodülleri optimal ya da optimal olmayan cerrahiyi tanımlar (7). Over kanserleri kemoterapiye oldukça duyarlı olup, tedavide kemoterapinin yeri önemlidir. Over kanserinde temel tedavi Karboplatin-Paklitaksel kemoterapisidir $(4,8,9)$. Kemoterapinin etkinliğinin yanısıra hastalar da gözlenen tedavi ilişkili yan etkiler de olabilmektedir. Uygulanan ajana bağlı bulantı, kusma, artralji, myalji, mukozit myelosüpresyon, febril nötropeni, siv1 retansiyonu, tırnak değişiklikleri, hipersensitivite reaksiyonu, periferik nöropati, renal toksisite, işitme bozukluğu, pulmoner ve kardiyotoksisite gibi yan etkiler görülebilmektedir (10). Çalışmamızda merkezimizde takip ettiğimiz over kanserli hastalarda uygulanan tedaviler, tedaviler ile ilişkili sağkalım sonuçları ve yan etkilerin değerlendirilmesi amaçlanmıştır.

\section{GEREÇ VE YÖNTEM}

$\mathrm{Bu}$ araştırma Sağlık Bilimleri Üniversitesi Ankara A.Y. Onkoloji hastanesinde Ocak 2010 ile 2020 yılları arasında tanı almış ve/veya tedavi edilmiş olan over kanseri vakalarının retrospektif olarak incelenmesine dayanmaktadır. Çalışmada izlemde tüm over kanserli hastalarda PFS, GS ve nüks oranlarının tespiti amaçlanmıştır.

Toplam 180 kadın hastanın over kanseri ile tedavi edildiği tespit edilmiştir. $\mathrm{Bu}$ vakalardan 7 tanesinin takip, tedavi ve sağkalım verilerine ulaşılamadığından çalışma dışı bırakılmıştır. Epitelyal over kanseri dışı over tümörleri çalışma dışı bırakılmıştır ( 9 vaka granulosa hücreli tümör, 3 vaka karsinosarkom, 1 vaka yolk sac tümörü). Şekil-1'de vakaların dahil edilme ve dişlama kriterlerine göre özellikleri gösterilmiştir.

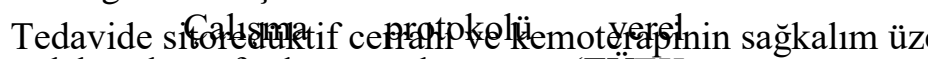
bilimsel kurul tarafindan onaylanmıştır (TÜEK 91-07.04.2020) FIGO (Uluslararas1 Jinekoloji ve Obstetrik Federasyonu) yönergelerine göre tam veya optimal sitoredüksiyon ile tedavi edilen Evre I-III hastalıği olan, neoadjuvan tedavi sonrası opere edilip adjuvan tedavi alan ve tanı anında metastatik hastalar dahil tüm evre grupları dahil edildi. Tüm EOK hastalarına adjuvan rejimi olarak Karboplatin (eğri altındaki alan-AUC: 5)- Paklitaksel $\left(175 \mathrm{mg} / \mathrm{m}^{2}\right)$ verildi. Bütün adjuvan tedavi şemaları 21 günlük 6 döngüde uygulandı. Sağkalım verileri bu kriterler göz önünde tutularak tabakalandırıldı. Over kanseri histolojisi, tanı yaşı, tanı tarihi, tanı anındaki hastalığın evresi, hastalık derecesi, asit ve/veya lenf nodu tutulumu varlığ1, kemoterapi tipi, kemoterapi döngü sayısı, tedaviye yanıt süresi, kemoterapi esnasında yaşanan toksisite bulguları ve derecesi, nüks tarihi verileri, elektronik bilgi sisteminden veya basilı yazılı hasta dosyalarından elde edilmiştir. Tüm epitelyal over kanseri alt tipleri dahil edildi.

Progresyonsuz sağkalım

(PFS): Tanıdan nükse kadar geçen süre (ay) olarak tanımlandı. Genel sağkalım (GS): Tanı tarihinden son görülme tarihine kadar geçen süre olarak (ay) hesaplandı. Sağkalım analizi için Kaplan-Meier yöntemi kullanıldı. PFS ve GS'deki faktörleri araştırmak için log-rank testi 
Orijinal çalışma

kullanıldı. Güven aralığı çalışma sırasında \%95 olarak kabul edildi $(\leq 0.05)$. İstatistiksel analiz için IBM SPSS sürüm 20 (BM Inc; Armonk, NY, ABD) kullanıld1.

\section{BULGULAR}

Toplam 160 vaka incelemeye alındı. Tüm grubun ortanca yaşı $61 \pm 11$ yıl idi. Hastaların klinik, patolojik ve cerrahi özellikleri Tablo 1'de özetlenmiştir. Histopatolojik alt gruplara göre seröz EOK en s1k $(\% 80.6)$ idi, daha sonra sırasiyla; endometrioid (\%8.2), müsinöz (\%10) ve berrak hücre tipleri $(\% 5)$ gözlendi. Tanı sırasındaki evre dağılımı incelendiğinde seröz EOK hastalarına çoğunlukla Evre III ile tanı alırken, endometroid tip ve müsinöz tip EOK Evre I ve II'de ve berrak hücreli EOK hastalarına çoğunlukla Evre I'de tanı konulduğu görüldü. Neaodjuvan tedavi \%16.9 hastaya verilmiş iken tanı anında metastatik hastaların oran1 yalnızca \%5.6 idi.

Kemoterapi esnasinda alopesi tüm vakalarda saptanmış iken; alopesi dışında herhangi bir yan etki görülme insidans $\% 51.2$ olarak saptandi. En sık görülen yan etki halsizlik (\%56.2) olarak saptandi. Bu yan etkiyi sırasıyla nötropeni (\%48.1), iştahsızlık (\%41.9) ve nöropati (\%39.4) izlemekteydi. Advers olay nedeniyle kemoterapi doz azaltımı toplam 56 vakada (\%38.9) gerçekleşmişti. Advers olaylar

Tablo 1: Vakaların Özellikleri
Tablo 2' de özetlenmiştir.

Ortalama takip süresi 39 ay (aralık: 1-108 ay) idi. Toplam 160 hastadan hepsi en az bir basamak tedavi almıştı. Takip süresi boyunca 78 vakada (\%48.8) nüks hastalık saptanmıştı. Bu nüks saptanan vakalardan \%64'ünde platin duyarlı nüks gelişmiş idi. Seröz EOK grubunda $\% 52.4$ oranında nüks saptanırken bu oran müsinöz kanserde $\% 40.0$; endometrioid tip kanser hastalarında \%36.3 olarak saptand1. Medyan progresyonsuz sağkalım 19.1 ay (\%95 Güven aralığı-GA: 18.125.7) olarak hesapland1 (Şekil 2). Kemoterapi yan etkisi nedeniyle doz redüksiyonu yapılan vakalar ile tam doz tedavi alan vakalar arasından progresyonsuz sağkalım açısından anlamlı fark saptanmadı. Benzer şekilde seröz ve seröz dışı histopatolojiler progresyonsuz sağkalım açısından kiyaslandığında arada anlamlı fark $\begin{array}{lll}\text { saptanmadi. } & \text { Toplam } 39\end{array}$ vakada (\%24.4) kansere bağl1 mortalite gerçekleşmişti. Tüm grupta genel sağkalım 89.9 ay (\%95 GA: 66.1-113.7) olarak saptandı. (Şekil 3). Endometrioid EOK ve berrak hücreli EOK'de medyan sağ kalıma ulaşılamamış iken seröz histopatolojik grubunda 76.6 ay (\%95 GA: 63.3-90.1) olarak hesapland1. Yan etki nedeniyle doz azaltımı yapılan vakalarda genel sağkalım anlamlı olarak daha az saptandı (p: 0.004, Şekil 4)

\begin{tabular}{|l|l|l|}
\hline \multicolumn{2}{|l|}{ Toplam sayı: 160} & $\mathrm{n}(\%)$ \\
\hline \multicolumn{2}{|l|}{ Histopatoloji } & $131(81.9)$ \\
\hline & Seröz EOK & $10(6.3)$ \\
\hline & Berrä̌z EOK Hücreli EOK & $8(5.0)$ \\
\hline & Endometrioid EOK & $11(6.9)$ \\
\hline Hastalık Evres* & $8(5.0)$ \\
\hline & Evre IA & $3(1.9)$ \\
\hline & Evre IB & \\
\hline
\end{tabular}


OAOT/

\begin{tabular}{|c|c|c|}
\hline & Evre IC & $23(14.4)$ \\
\hline & Evre IIA & $9(5.6)$ \\
\hline & Evre IIB & $5(3.1)$ \\
\hline & Evre IIC & $19(11.9)$ \\
\hline & Evre IIIA & $6(3.8)$ \\
\hline & Evre IIIC & $67(41.9)$ \\
\hline & Evre IV & $10(6.3)$ \\
\hline \multicolumn{2}{|c|}{ HIPEC Uygulamas1 } & $19(11.9)$ \\
\hline \multicolumn{2}{|c|}{ Cerrahi Tipi } & \\
\hline & $\mathrm{R} 1$ & $29(18.1)$ \\
\hline Neoadjuv & an Tedavi Alan Hasta Grubu & 27 (16.9) \\
\hline \multicolumn{3}{|c|}{$\begin{array}{l}\text { HIPEC: Hipertermik İntraperitoneal Kemoterapi } * \text { FIGO Evrelendirmesi (International Federation of Gynecology and } \\
\text { Obstetrics-Uluslararası Jinekoloji ve Obstetrik Federasyonu) }\end{array}$} \\
\hline
\end{tabular}

Tablo 2. Advers Olaylar

\begin{tabular}{|l|l|}
\hline Toplam say1: 160 & $\mathrm{n}(\%)$ \\
\hline Alopesi & $160(100)$ \\
\hline Halsizlik & $90(56.2)$ \\
\hline Bulantı & $75(46.9)$ \\
\hline Kusma & $56(35.0)$ \\
\hline Iştahsızlık & $67(41.9)$ \\
\hline Nötropeni & $77(48.1)$ \\
\hline Trombositopeni & $68(42.5)$ \\
\hline Nöropati & $63(39.4)$ \\
\hline Allerji & $25(15.6)$ \\
\hline
\end{tabular}




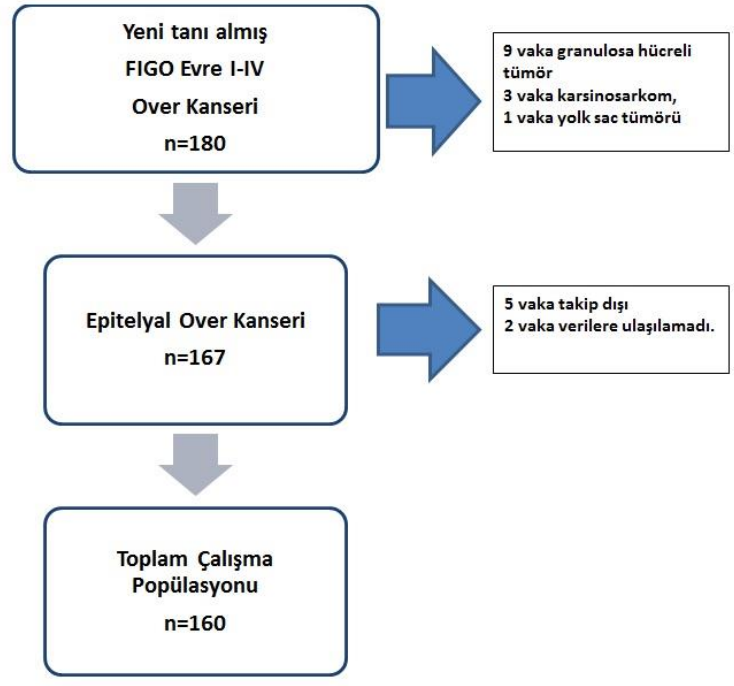

Şekil 1: Veri akış diagramı

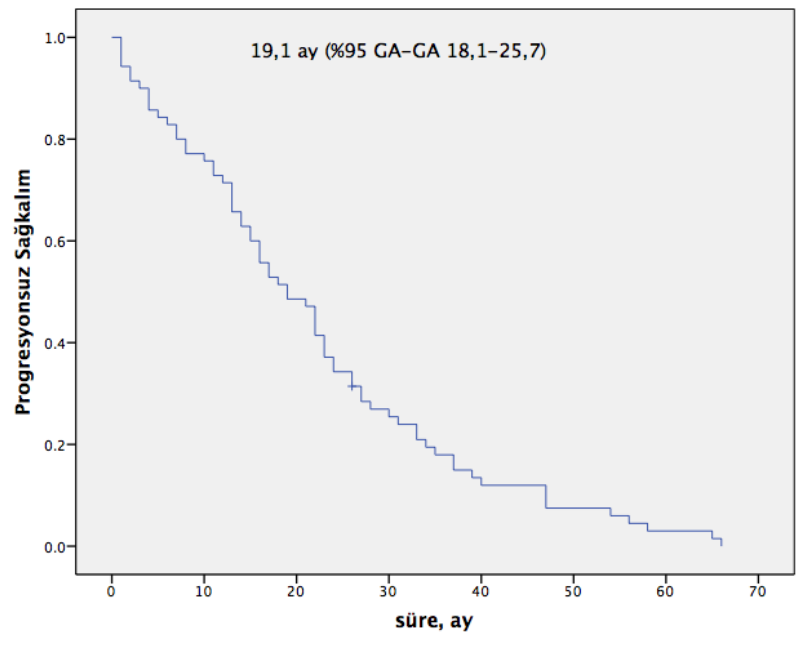

Şekil 2: Progresyonsuz sağkalım

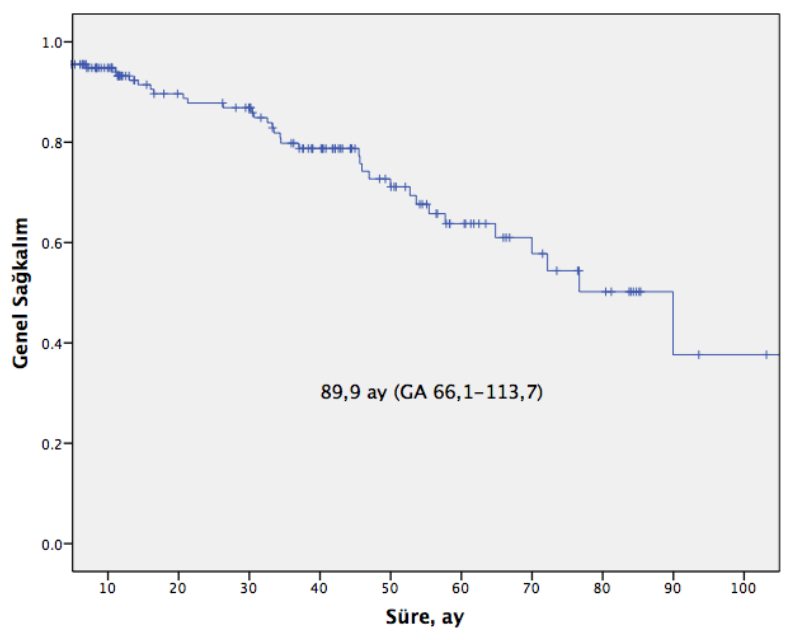

Şekil 3: Genel sağkalım

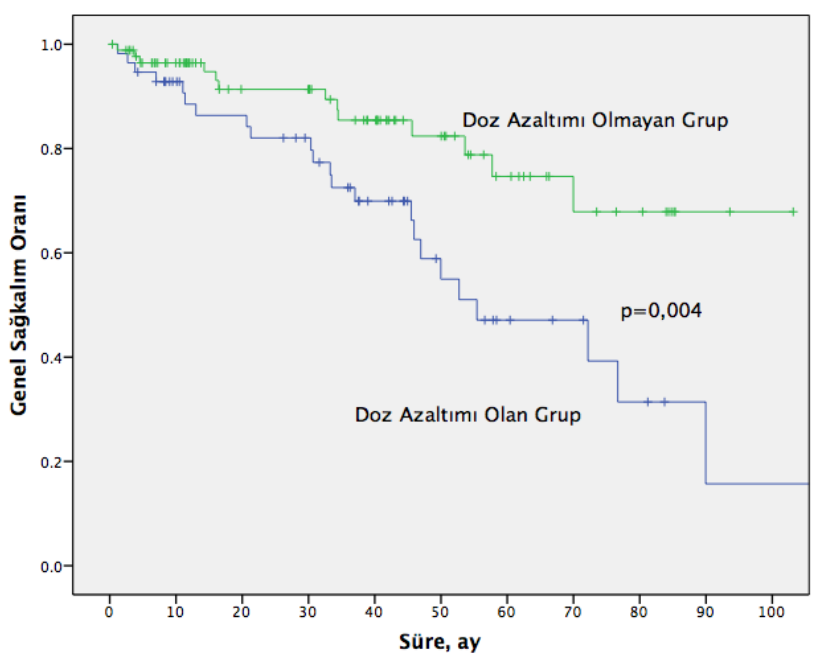

Şekil 4: Kemoterapi doz azaltımı yapilan ve yapılmayan grupların genel sağkalım açısından kıyaslanması 


\section{TARTIŞMA}

Orijinal çalışma

Over kanserleri, meme kanseri gibi daha sik görülen tümörlere göre belirgin şekilde daha düşük insidans oranlarına sahip olsa da spesifik biyobelirteç ve etkili tanı yöntemlerinin eksik oluşu nedeniyle çoğu zaman geç tanı almakta ve metastaz yapana kadar fark edilememektedir. $\mathrm{Bu}$ nedenle birçok kansere göre düşük insidansa sahip olmasına rağmen, kansere bağlı ölümler incelendiğinde jinekolojik maligniteler arasında ilk, tüm kanser türleri arasında ise beşinci sıradaki ölüm nedenidir (11).

Meme kanserinde olduğu gibi, östrojen ve hormon tedavisi (tamoksifen, letrozol, anastrozol) EOK'da önemli bir rol oynamaktadır $(12,13)$. Menopoz sonras1 16,608 olgunun incelendiği bir araştırmada kombine östrojen progesteron tedavisinden sonra EOK insidansında anlamlı şekilde artışın olduğu bildirilmiştir (14). Kuzey Amerika'da elde edilen veriler ise kadınların sıklıkla menopoz sonrasında EOK tanısı aldığını göstermektedir ve olguların yaklaşık \%50'si 60 yaş ve üzeri kadınlardan oluşmaktadır. Brezilya merkezli yapılan bir çalışmada EOK tanısı alan olguların ortalama yaşlarının $54.67 \pm 13.84$ olduğu bildirilmiştir (15). Yaptığımız çalışmada EOK tanıs1 alan olgularımızın ortalama yaşı $61 \pm 11$ olarak saptanmış olup bu konuda yapılmış diğer çalışmalar ile uyumluluk göstermektedir.

Epitelyal over tümörleri tüm over tümörlerinin $\% 75$ 'ini ve over kökenli malignitelerin \%90-95'ini oluşturmaktadır (16). Yapılan geniş kapsamlı bir çalışmada toplam 23,484 over kanserli olgu 117 farklı histolojik gruba ayrılmış ve incelen tüm olguların \%95.3'ünü EOK oluşturmuştur (1). Ülkemizde yapılan bir çalışmada ise primer over tümörü olan 84 olgu incelenmiş ve olguların \%70.4'ünün EOK olduğu bildirilmiştir (17). Over tümörlerinin ilk sebebi olması ve jinekolojik tümörler arasında en yüksek mortalite oranına sahip oluşu nedeniyle EOK çoğu over kanseri araştırmasının odak noktası olduğu gibi bizim çalışmamızın da temelini oluşturmaktadır. Çalışmamızda incelediğimiz 180 olgunun \%92.77'sini EOK'lu olgular oluşturmuş, yapılan ulusal ve uluslararası çalışmalarla benzer bir sonuç elde edilmiştir.

Over kanserlerinin araştırıldığ1

çalışmaların büyük çoğunluğunda seröz karsinom en sik saptanan EOK türü olarak bildirilmektedir (18-20). Epitelyal over tümörlerinin histolojik tiplerine göre incelendiği bir araştırmada 165 EOK'lu olgu arasında 88 olgu ile en sik seröz karsinom görülmüştür. Seröz tipi sırasıyla 40 olgu ile musinöz, 15 olgu ile endometrioid ve 13 olgu ile berrak hücreli EOK izlemiştir (18). Ülkemizde yapılan çalışmalarda da seröz tip en sik saptanan EOK histolojik tipi olarak görülmektedir $(17,21)$. Yaptığımız çalışmada literatür verileriyle uyumlu olarak en sik saptanan histolojik EOK tipi seröz EOK olmuş (\%81.9) ve bunu sirasıyla endrometrioid (\%6.9), müsinöz (\%6.3) ve berrak hücreli (\%5.0) EOK histolojik tipleri takip etmiştir.

Müsinöz ve berrak hücreli EOK kısmen daha erken evrelerde tanı alsa da özellikle over kanserlerinin büyük çoğunluğunu oluşturan seröz tip EOK en sik Evre III'de saptanmaktadır (3). Siyah ve beyaz 1rk üzerinde over kanserinin hangi evrede saptandığını araştıran bir çalışmada hem siyah hem de beyaz kadınlarda over kanserinin en sik Evre III'de saptandığı, ikinci sıklıkta Evre I'de saptandığ1 bildirilmiş, Evre II ve Evre IV ise eşit oranda sonuncu olmuşlardır (22). Çalışmamızda diğer çalışmalara benzer şekilde olgular en sık (\%50.1) Evre III'de tanı almış ve bunu sirasıyla Evre I (\%21.3), Evre II (20.6) ve Evre IV (\%6.3) izlemiştir. Tanı aşamasındaki evre dağılımı incelendiğinde seröz EOK olguları çoğunlukla Evre III'de saptanmış, müsinöz tip EOK Evre I ve II'de ve berrak hücreli EOK olgularına ise en sık Evre I'de tanı konulmuştur.

Over

kanserlerinin sıklıkla geç tanı alması genel sağkalım oranlarında kemoterapinin önemini artırmaktadır. Yapılan bir çalışmada genel sağkalım oranları ile kemoterapi arasında anlamlı ilişkiden bahsedilmektedir (8). Kemoterapi esnasında görülen yan etkiler tedavi rejiminde değişikliklere veya doz azaltımına neden olmaktadır. Literatürde en sik görülen yan etki alopesi olarak belirtilirken, doz azaltımına en s1k neden olan yan etki ise nötropeni olarak bildirilmektedir. Doz azaltımı ile sağkalım oranları hakkında farklı sonuçların olduğu çalışmalar mevcuttur $(23,24)$. Nagel ve ark. yaptıkları çalışmada over kanserinde doz azaltımı ile genel sağkalım ve progresyonsuz sağkalım arasında anlamlı bir ilişki bulamadıklarını belirtmiştir (23). Araştırmamızda diğer çalışmalara benzer şekilde ele aldığımız olguların tamamında alopesi görülmüş olup, \%56.2'sinde halsizlik ve 


\section{Orijinal çalışma}

\%48.1'inde nötropeni saptanmıştır. Advers olaylar nedeniyle \%38.9 olguda doz azaltımı yapılmıştır. Doz azaltımı ile progresyonsuz sağkalım arasında anlamlı bir ilişki saptanamamış olup ( $>0.05)$ doz azaltımı yapılan olgularda genel sağkalım anlamlı şekilde düşük bulunmuştur ( $\mathrm{p}<0.05)$.

Çalışmamızın retrospektif bir araştırma olması, EOK dışındaki malignitelerin inceleme kapsamına alınmaması, yaş gruplarının ayrı ayrı değerlendirilmemesi ve olguların eşlik eden hastalıklarının sağkalım oranları üzerindeki etkilerine bakılmaması araştırmamızın eksik yönlerini oluşturmaktadır.

\section{SONUÇ}

Sonuç olarak over kanseri çoğu zaman geç saptanması ve mortalitesinin yüksek oluşu ile mortal bir hastalıktır. Bu çalışma ile over kanseri üzerine dikkat çekilmiş ve bu konuda eksikliği göze çarpan durum tanı ve tarama yöntemlerine olan ihtiyaçtır. Yan etkiler nedeniyle doz azaltımının olduğu hastalarda üzerindeki sağkalımın anlamlı şekilde düşük bulunmas1 optimal dozda tedavinin önemini göstermektedir.

\section{Çıkar Çatışması: Yok}

\section{REFERANSLAR}

1. Quirk JT, Natarajan N. Ovarian cancer incidence in the United States, 1992-1999. Gynecol Oncol. 2005;97:519-23.

2. Desai A, Xu J, Aysola K, et al. Epithelial ovarian cancer: An overview. World J Transl Med. 2014;3:1-8.

3. Chien J, Poole EM. Ovarian Cancer Prevention, Screening, and Early Detection: Report From the 11th Biennial Ovarian Cancer Research Symposium. Int J Gynecol Cancer. 2017;27:S20-S22.

4. Lheureux S, Braunstein M, Oza AM. Epithelial ovarian cancer: Evolution of management in the era of precision medicine. CA Cancer J Clin. 2019;69:280-304.

5. Mallen A, Soong TR, Townsend MK, Wenham RM, Crum CP, Tworoger SS. Surgical prevention strategies in ovarian cancer. Gynecol Oncol. 2018;151:16675.

6. Javadi S, Ganeshan DM, Qayyum A, Iyer RB, Bhosale P. Ovarian Cancer, the Revised FIGO Staging System, and the Role of Imaging. AJR Am J Roentgenol. 2016;206:1351-60.
7. Cortez AJ, Tudrej P, Kujawa KA, Lisowska KM. Advances in ovarian cancer therapy. Cancer Chemother Pharmacol. 2018;81:17-38.

8. Ozols RF, Bundy BN, Greer BE, et al. Phase III trial of carboplatin and paclitaxel compared with cisplatin and paclitaxel in patients with optimally resected stage III ovarian cancer: a Gynecologic Oncology Group study. J Clin Oncol. 2003;21:3194-200.

9. Armstrong DK, Bundy B, Wenzel L, et al. Intraperitoneal cisplatin and paclitaxel in ovarian cancer. $\mathrm{N}$ Engl J Med. 2006;354:34-43.

10. Bhugwandass CS, Pijnenborg JM, Pijlman B, Ezendam NP. Effect of chemotherapy on health-related quality of life among early-stage ovarian cancer survivors: a study from the population-based PROFILES registry. Curr Oncol. 2016;23:e556-e62.

11. Tayassoli F. Tumours of the breast and female genital organs. Pathology and genetics of tumors of the digestive system. 2003:10-80.

12. Cunat S, Hoffmann P, Pujol P. Estrogens and epithelial ovarian cancer. Gynecol Oncol. 2004;94:25-32.

13. Imamoglu GI, Eren $\mathrm{T}$, Arzu O, Yıldırım N, Karacin C, Baylan B. Is Tamoxifen Use a Factor Affecting Continence in Breast Cancer Patients? Cureus. 2019;11:18.

14. Anderson GL, Judd HL, Kaunitz AM, et al. Effects of estrogen plus progestin on gynecologic cancers and associated diagnostic procedures: the Women's Health Initiative randomized trial. JAMA. 2003;290:1739-48.

15. Paes MF, Daltoé RD, Madeira KP, et al. A retrospective analysis of clinicopathological and prognostic characteristics of ovarian tumors in the State of Espírito Santo, Brazil. Journal of ovarian research. 2011;4:14.

16. Zhang X-Y, Zhang P-Y. Recent perspectives of epithelial ovarian carcinoma. Oncol Lett. 2016;12:3055-58. 17. Turgut A, Özler A, Sak ME, ve ark. Jinekolojik kanserli olguların retrospektif analizi: 11 yıllık deneyim. J Clin Exp Invest www jceionline org Vol. 2012;3:209-13.

18. Inai K, Shimizu Y, Kawai K, et al. A Pathology Study of Malignant and Benign Ovarian Tumors Among Atomic-Bomb Survivors-Case Series Report-. J Radiat Res (Tokyo). 2006;47:49-59.

19. Lurie G, Wilkens LR, Thompson PJ, Matsuno RK, Carney ME, Goodman MT. Symptom presentation in invasive ovarian carcinoma by tumor histological type and grade in a multiethnic population: a case analysis. Gynecol Oncol. 2010;119:278-84.

20. Loka A, Tsukuma H, Ajiki W, Oshima A. Ovarian cancer incidence and survival by histologic type in Osaka, Japan. Cancer Sci. 2003;94:292-96.

21. Müderris İI, Ünal A, Karahacioğlu E, Çetin M, Altınbaş M. Combination chemotherapies in advanced ovarian cancer.

22. Kim S, Dolecek TA, Davis FG. Racial differences in stage at diagnosis and survival from epithelial ovarian cancer: a fundamental cause of disease approach. Soc Sci Med. 2010;71:274-81.

23. Nagel C, Backes FJ, Hade E, et al. Effect of chemotherapy delays and dose reductions on progression free and overall survival in the treatment of epithelial ovarian cancer. Gynecol Oncol. 2012;124:221-24.

24. Christian J, Thomas H. Ovarian cancer chemotherapy. Cancer Treat Rev. 2001;27:99-109. 